\title{
Near-surface diurnal warming simulations: validation with high resolution profile measurements
}

\author{
B. Scanlon ${ }^{1}$, G. A. Wick ${ }^{2}$, and B. Ward ${ }^{1}$ \\ ${ }^{1}$ School of Physics and Ryan Institute, National University of Ireland, Galway, Ireland \\ ${ }^{2}$ NOAA ESRL PSD, 325 Broadway Boulder, CO 80305, USA \\ Correspondence to: B. Ward (bward@nuigalway.ie) \\ Received: 28 September 2012 - Published in Ocean Sci. Discuss.: 20 December 2012 \\ Revised: 15 October 2013 - Accepted: 18 October 2013 - Published: 19 November 2013
}

\begin{abstract}
.
Sea surface temperature (SST) is an important property for governing the exchange of energy between the ocean and the atmosphere. Common in situ methods of measuring SST often require a cool-skin and warm-layer adjustment in the presence of diurnal warming effects. A critical requirement for an ocean submodel is that it can simulate the change in SST over diurnal, seasonal and annual cycles. In this paper we use high-resolution near-surface profiles of SST to validate simulated near-surface temperature profiles from a modified version of the Kantha and Clayson 1-D mixed-layer model. Additional model enhancements such as the incorporation of a more recent parameterization of turbulence generated by wave breaking and a recent solar absorption model are also validated. The model simulations show a strong variability in highly stratified conditions, with different models providing the best results depending on the specific criteria and conditions. In general, the models with enhanced wave breaking effects provided underestimated temperature profiles while the more coarse baseline and blended approaches produced the most accurate SST estimates.
\end{abstract}

\section{Introduction}

Accurate measurements of sea surface temperature (SST) for the upper ocean are important for air-sea exchange of heat (Fairall et al., 1996b) and gas (Ward et al., 2004a). It has been shown that SST values with an accuracy of $\pm 0.2 \mathrm{~K}$ are required to compute the air-sea heat fluxes to an accuracy of $10 \mathrm{~W} \mathrm{~m}^{-2}$ (Fairall et al., 1996a). Bulk formula heat flux calculations rely on SST values to compute sensible and la- tent turbulent heat fluxes as well as emitted longwave radiation from the ocean surface, and these models are most sensitive to SST variability in the lower latitudes. According to Fairall et al. (1996b) the most appropriate value of SST for these formulae is the temperature of the cool-skin layer, known as the skin temperature $\left(\mathrm{SST}_{\text {Skin }}\right)$. The coolskin layer (or the molecular sublayer) is $\sim 1 \mathrm{~mm}$ thick, and is the upper most layer of the sea surface and is in direct contact with the atmosphere. The skin temperature is cooled by the combined effects of the net longwave radiative flux, the sensible heat flux and the latent heat flux and is typically $0.1-0.5 \mathrm{~K}$ lower than the temperature of the subskin layer immediately below (Wick et al., 1996; Donlon et al., 2002). The cool skin is almost always present, although its total effect may be compensated by the presence of a warm layer (Fairall et al., 1996b). Common in situ methods of SST measurement obtain temperature at a depth, often $1-4 \mathrm{~m}$, called $T_{\text {depth}}$, or commonly the bulk temperature measurement. These bulk temperatures are the most commonly available measurements obtained from buoys and ships (Gentemann et al., 2009). It is often required that these bulk measurements be adjusted for diurnal warm-layer and cool-skin effects.

In the upper ocean, diurnal warming cycles occur due to the solar heating and oceanic heat loss fluctuations (Price et al., 1986) and are responsible for high variations of SST. For example, in summer heating conditions with low wind, the depth of the diurnal warm layer can typically be on the order of $1 \mathrm{~m}$ (mean depth), and the surface amplitude (skin temperature minus bulk temperature) can be as large as $3 \mathrm{~K}$ (Stramma et al., 1986; Soloviev and Lukas, 1996). In such conditions, turbulent mixing near the surface is mainly driven 
by wind-induced shear and convection. This convection is driven by densification due to evaporation and possible net surface cooling. Daytime solar heating effects within a stratified upper ocean are isolated to the surface layers. The heating of these layers create a positive buoyancy flux which restricts deepening of the warm layer (Soloviev and Lukas, 1996), further enhancing the effects of stratification. In moderate wind conditions, solar heat is mixed vertically to a greater depth than what can be achieved directly by radiation. In such cases, the positive surface buoyancy fluxes are overcome by wind driven shear which deepens the diurnal warm layer typically to $10 \mathrm{~m}$ depth. In turn, the surface amplitude is typically reduced to $0.2 \mathrm{~K}$ (Price et al., 1986).

Previous studies using models and near-surface temperature profile measurements have demonstrated the potential for significant variability in the near-surface temperature especially during the daytime at low winds and with strong solar heating (Fairall et al., 1996a; Soloviev and Schluessel, 1996; Webster et al., 1996; Donlon, 1999; Gentemann and Minnett, 2009; Gentemann et al., 2009). Clearly, onedimensional models which only consider transport in the vertical direction have limitations and cannot account for advective effects. Advection can introduce errors in modelled temperature gradients from horizontal currents of a different temperature as noted by Kantha and Clayson (1994). The 1-D models, however, can be very informative in evaluating the mixing processes associated with stratification and diurnal warming. The goal of this paper is to compare model simulations to observed high resolution temperature profile measurements in low to moderate wind and high solar irradiance environments to evaluate the model's skill to accurately reproduce the temperature profile. It is important to note that this study evaluates the ability of the models to exactly reproduce a specific realization of observations. It does not address a more traditional statistical evaluation of model uncertainty.

Observed temperature profiles of the upper $5 \mathrm{~m}$ of the ocean were measured by the Skin Depth Experimental Profiler (SkinDeEP) (Ward et al., 2004b) and also by its successor the Air-Sea Interaction Profiler (ASIP) (Ward et al., 2012). The profiles presented here were obtained during three separate field experiments: Gulf of California in 1999 (hereafter GC99), Gulf of Lions (Mediterranean) in 2003 (hereafter GL03), and the Indian Ocean in 2007 (hereafter IO07). SkinDeEP is an autonomous profiler capable of measuring temperature to a sub-centimetre resolution. At it's typical rising velocity of $0.5 \mathrm{~m} \mathrm{~s}^{-1}$, the resolution is $3 \mathrm{~mm}$ (see Ward et al. (2004b) for a complete description of SkinDeEP). ASIP is similar in concept to SkinDeEP, but has a much larger sensor range, can profile to $100 \mathrm{~m}$, and has a larger battery capacity. Coupling the high resolution profile data from the near-surface along with M-AERI radiometric data of the true skin temperature, provides a complete temperature profile of the upper ocean.

This article attempts to validate the model simulations of a 1-D second moment turbulence closure mixed-layer model based on Kantha and Clayson (1994) for the GC99, GL03, and IO07 time periods, using available meteorological data and bulk measurements while neglecting the effects of advection. Further refinements to the model, including wave breaking effects (Kantha and Clayson, 2004) and a recent solar transmission model (Ohlmann and Siegel, 2000), are incorporated into the model for validation. Section 2 discusses the cruise data, instrumentation and provides a theoretical background for the models used in this study. Section 3 shows the results from the comparisons of the measured SkinDeEP data and the modelled simulations, followed by our conclusions.

\section{Material and methods}

\subsection{Instruments}

The surface temperature profiles were obtained from either SkinDeEP (Ward et al., 2004b) or ASIP (Ward et al., 2012). Both of these instruments are autonomous vertical profilers designed to study the upper ocean with high resolution sensors. For this study, we are concerned with temperature profiles in the upper $5 \mathrm{~m}$, which are provided by the FP07 thermometer mounted on both profilers.

SkinDeEP has the ability to obtain more than 100 consecutive profiles without intervention and contains a CPU capable of high-frequency sampling and data storage (Ward, 2006). Autonomous profiling is accomplished with a volume adjusted buoyancy variance system. While in operation, it was attached to a spar buoy via $50 \mathrm{~m}$ of a synthetic, high breaking strain tether line. Profiling started with the instrument sinking to its programmed depth which was monitored by the onboard external pressure sensor, at which the buoyancy was changed to positive and temperature measurements were acquired as it rose to the surface. The temperature data was provided with the FP07 thermistor, which was calibrated against a slower, accurate thermometer.

ASIP is an autonomous vertically profiling instrument designed to profile from below so as to provide undisturbed measurements all the way to the surface. It is equipped with high resolution sensors for the measurement of temperature, salinity, light, oxygen, and turbulence. There are three thrusters which submerge it to a programmed depth (maximum $100 \mathrm{~m}$ ), whereupon it ascends through the water column towards the surface under its own buoyancy, recording data at $1000 \mathrm{~Hz}$, generating 192 kbytes s$^{-1}$ which is stored with a single board computer.

The skin temperature for all cruises was continuously measured by the Marine-Atmospheric Emitted Radiance Interferometer (M-AERI, Minnett et al., 2001); a passive infrared radiometric interferometer which makes radiance measurements in the $500-3000 \mathrm{~cm}^{-1}$ wave number range with a resolution of $0.5 \mathrm{~cm}^{-1}$. The radiometer comprises of a gold rotating mirror that allows for both sea and sky views at complementary angles to nadir and zenith. The accuracy of the 
Table 1. Times, location and number of profiles for the deployments of the three case studies.

\begin{tabular}{llllll}
\hline Region & Date & Time (Local) & Latitude & Longitude & \# of profiles \\
\hline GC99 & 283 & $11: 12-14: 13$ & $22^{\circ} 31.48 \mathrm{~N}$ & $109^{\circ} 35.43 \mathrm{~W}$ & 161 \\
GL03 & $113 / 114$ & $23: 08-11: 23$ & $42^{\circ} 18.47 \mathrm{~N}$ & $5^{\circ} 05.65 \mathrm{E}$ & 117 \\
IO07 & $39 / 40$ & $19: 02-7: 20$ & $7^{\circ} 59.77 \mathrm{~S}$ & $67^{\circ} 27.70 \mathrm{E}$ & 72 \\
\hline
\end{tabular}

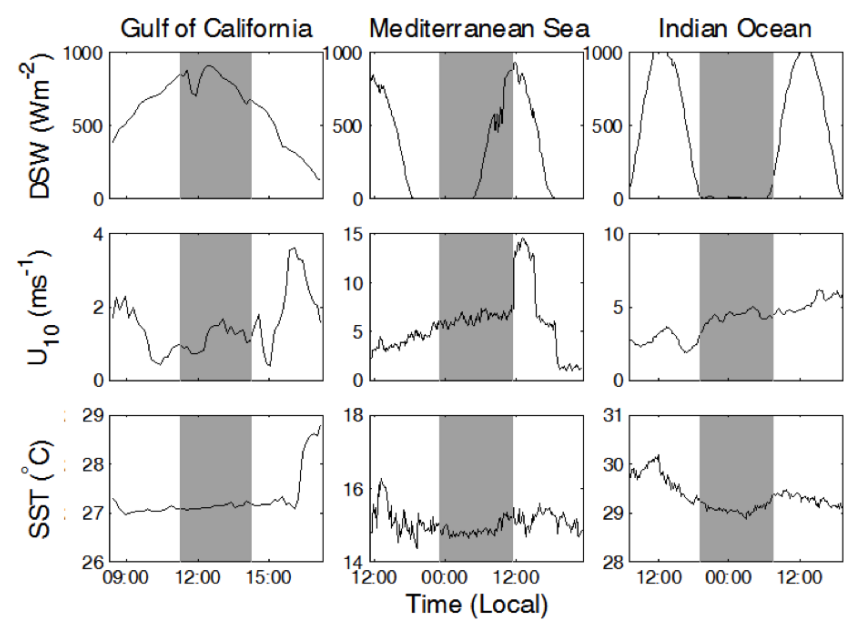

Fig. 1. Time series of the downwelling shortwave radiation, wind speed, and skin temperature for the GC99, GL03 and IO07 periods respectively. The grey vertical column marks the time of the deployment period. The data is 60 min averaged.

derived SST measurements are better than $0.05 \mathrm{~K}$ (Minnett et al., 2001). Real-time calibration is continuously carried out by viewing two internal blackbody cavities, one set to $60^{\circ} \mathrm{C}$ and the other to ambient temperature.

The M-AERI skin temperature and SkinDeEP/ASIP temperature profile measurements used collectively create a high resolution temperature profile of the upper few metres of the sea surface.

\subsection{Observations}

The GC99 data set was obtained over a 12 day period in October 1999 near Baja California. Ten successful deployments of SkinDeEP (denoted by the day of month) were obtained, leading to a total of 976 high resolution upper ocean profiles. The deployments were carried out from the R/V Melville mainly during early afternoon periods when the waters were maximally stratified. Over the 12 days, the solar heat flux was high and the wind varied from $1-9 \mathrm{~m} \mathrm{~s}^{-1}$. For each day the downwelling shortwave radiation reached over $800 \mathrm{~W} \mathrm{~m}^{-2}$ and wind speeds were relatively low with a mean range of $3.5 \pm 1.8 \mathrm{~m} \mathrm{~s}^{-1}$ across all the deployments. Deployment 10 occurs in idealized weather conditions for this study with a mean wind speed of $1.1 \mathrm{~m} \mathrm{~s}^{-1}$ and a mean shortwave radiation of $802 \mathrm{~W} \mathrm{~m}^{-2}$ (peaking at $912 \mathrm{~W} \mathrm{~m}^{-2}$ ) (Fig. 1). A full description of the GL99 meteorological conditions can be obtained in Ward (2006).

Additional data is provided by SkinDeEP from the GL03 experiment in the Gulf of Lions onboard the R/V Urania during April 2003. The profiler obtained 576 different profiles of the upper sea surface in 3 deployments over 3 days. Due to a technical error during deployment 1 and 2, SkinDeEP failed to successfully record temperature values in the upper metre. The error was corrected before the final deployment, 3, took place. For the basis of this paper, profiles from deployment 3 of this cruise are the only measurements deemed suitable and the rest shall be ignored. This deployment represents the situation where a well mixed nighttime water column is being subjected to strong morning-time solar heating. Solar shortwave radiation rises from a minimum value to $876 \mathrm{~W} \mathrm{~m}^{-2}$. The mean wind speed is $6.29 \pm 0.52 \mathrm{~m} \mathrm{~s}^{-1}$ for the period (Fig. 1).

The data collected from the IO07 cruise represents a high resolution view of the temperature structure in a highly stratified area of the Indian-Pacific warm pool, the "SeychellesChagos Thermocline Ridge". The 10th deployment of the cruise occurred on 8-9 February and resulted in 72 profiles captured in highly stratified conditions. The period started at 19:02 LT and finished at 07:21 the next morning. The mean wind speed was $4.35 \pm 0.38 \mathrm{~m} \mathrm{~s}^{-1}$. The solar heat flux ramped up from 0 to $102 \mathrm{~W} \mathrm{~m}^{-2}$ towards the end of the deployment (Fig. 1). Table 1 displays additional information regarding the GC99, GL03 and IO07 deployments.

For all three field campaigns, meteorological sensors were deployed to provide a time series of the following parameters: wind speed and direction; air temperature; relative humidity; barometric pressure; downwelling long- and shortwave radiation. There was also gyroscopic information available to determine the ship's speed, heading, and bearing for wind speed correction. Air-sea heat fluxes were calculated using the COARE bulk flux algorithms (Fairall et al., 1996b).

\subsection{Models}

Five variations of the Kantha and Clayson (1994) (KC94 hereafter) second moment closure, one-dimensional mixedlayer model provide 1 min resolution simulations of the upper ocean for the durations of the GC99, GL03 and IO07 cruises. The first, or, "baseline" configuration most closely corresponds to that described in KC94. The model name is shortened to "Base" for representation in tables and plots. 
Table 2. Summary of the five model versions used for evaluation.

\begin{tabular}{llll}
\hline $\begin{array}{l}\text { Model } \\
\text { version }\end{array}$ & $\begin{array}{l}\text { Solar } \\
\text { absorption }\end{array}$ & $\begin{array}{l}\text { Turbulence } \\
\text { coefficients }\end{array}$ & $\begin{array}{l}\text { near surface TKE } \\
\text { assumptions }\end{array}$ \\
\hline Base & PS81 & KC94 & Law of the wall \\
EWB & PS81 & KC94 & KC04 \\
Blend & PS81 & $\begin{array}{l}\text { KC94, } \\
\text { revised to KC04 }\end{array}$ & $\begin{array}{l}\text { Law of the wall for wind }<2 \mathrm{~m} \mathrm{~s}^{-1}, \\
\text { KC04 for wind }>2 \mathrm{~m} \mathrm{~s}^{-1}\end{array}$ \\
EST & OS00 & KC94 & KC04 \\
BST & OS00 & $\begin{array}{l}\text { KC94, } \\
\text { revised to KC04 }\end{array}$ & $\begin{array}{l}\text { Law of the wall for wind }<2 \mathrm{~m} \mathrm{~s}^{-1}, \\
\text { KC04 for wind }>2 \mathrm{~m} \mathrm{~s}^{-1}\end{array}$ \\
\hline
\end{tabular}

The basic turbulence scheme is that of KC94, but the vertical resolution is enhanced to simulate the details of the nearsurface temperature profile. A nine-wavelength band solar absorption model of Paulson and Simpson (1981) (PS81 hereafter) is used in this configuration to account for solar heating effects within the water column. It is a common assumption in ocean modelling to assume that the KarmanPrandtl law of the wall is valid near the air-sea interface. This assumption works well in shear flows adjacent to a rigid boundary but fails in the presence of breaking waves near the surface (Craig and Banner, 1994). This is due to the turbulent kinetic energy (TKE) equation being based on local shear production and dissipation near the surface. Kantha and Clayson (2004) (hereafter KC04) suggest that the influence of wave breaking strongly elevates the dissipation rate in the upper few metres of the ocean and the effects cannot be ignored (see also Terray et al., 1996; Agrawal et al., 1992). A second version of the model incorporating the TKE equation of $\mathrm{KCO} 4$ to account for these effects is termed the "enhanced wave breaking model" (shortened to EWB in figures). This addition incorporates TKE injection parameters due to breaking waves and Langmuir circulation. Weller and Price (1988) found that stratified thermal layers in shallow diurnal mixed layers can be rapidly destroyed by Langmuir circulation. Thus the inclusion of a parameter for Langmuir cells is important. The new parameterization for TKE input at the surface is proportional to a power law of the waterside friction velocity $u *$. The inclusion of these parameters increases TKE and dissipation rates in the upper ocean, leading to enhanced mixing in the mixed layer. $\mathrm{KC} 04$ reported the effects of including Langmuir circulation in the model resulted in lower SST values. The reader is referred to Kantha and Clayson (2004) for more information.

The third model used in this study is named the "blended model" (shortened to "blend" in figures). This model transitions between the use of the baseline model and the enhanced wave breaking model at a wind speed of $2 \mathrm{~ms}^{-1}$. The turbulence scheme below $2 \mathrm{~m} \mathrm{~s}^{-1}$ is that of the baseline model while it shifts toward that of the enhanced wave breaking model at higher winds. This blending was introduced in an attempt to reproduce the range of diurnal warming am- plitudes observed in previous shipborne observations of the surface temperature (not shown). The turbulence coefficients are also revised within this model to follow Kantha (2003).

Solar insolation is a very important parameter for the effects of diurnal warming. It has been reported that between 60 and $90 \%$ of solar irradiance is attenuated within the upper $10 \mathrm{~m}$ of the ocean (Ohlmann et al., 1998). Variations in the assumed absorption rate of insolation can have a significant effect on the simulated profiles. The "PS81" nine-band solar transmission model, of Paulson and Simpson (1981) is used for the three models described so far. This is also the scheme currently used in the Profiles of Ocean Surface Heating (POSH) model (Gentemann et al., 2009). This solar transmission model computes solar transmission through the airsea interface by fixing the sea surface albedo to a constant value of 0.055 which has been recorded to produce instantaneous errors of $\pm 40 \mathrm{~W} \mathrm{~m}^{-2}$ (Ohlmann and Siegel, 2000). The reader is referred to Fairall et al. (1996b) and Ohlmann and Siegel (2000) for further information.

The fourth model version tested incorporates a more recent solar absorption profile developed by Ohlmann and Siegel (2000) (hereafter OSO0) along with the "enhanced wave breaking model" and is called the "enhanced solar transmission model" (shortened to "EST" in figures). It is a twoequation solar transmission parameterization that depends on upper ocean chlorophyll concentration, cloud amount and solar zenith angle. In a high solar insolation and low wind condition study carried out by OSO0, they found the new parameterization to give a mean $12 \mathrm{~W} \mathrm{~m}^{-2}$ reduction in the quantity of solar radiation attenuated in the top few metres of the ocean compared with previous parameterizations. The new transmission parameterization gives a slightly deeper warm layer and a decrease in the warm-layer temperature correction which often reaches $0.2 \mathrm{~K}$ (Ohlmann and Siegel, 2000).

The final version of model tested is an enhancement of the "blended model". It transitions between the baseline and enhanced wave breaking models in the same fashion as the blended model but also incorporates the OSO0 two-equation solar transmission model described for the enhanced solar transmission model in place of the PS81 nine-band model. It is called the "blended solar transmission model" (shortened 


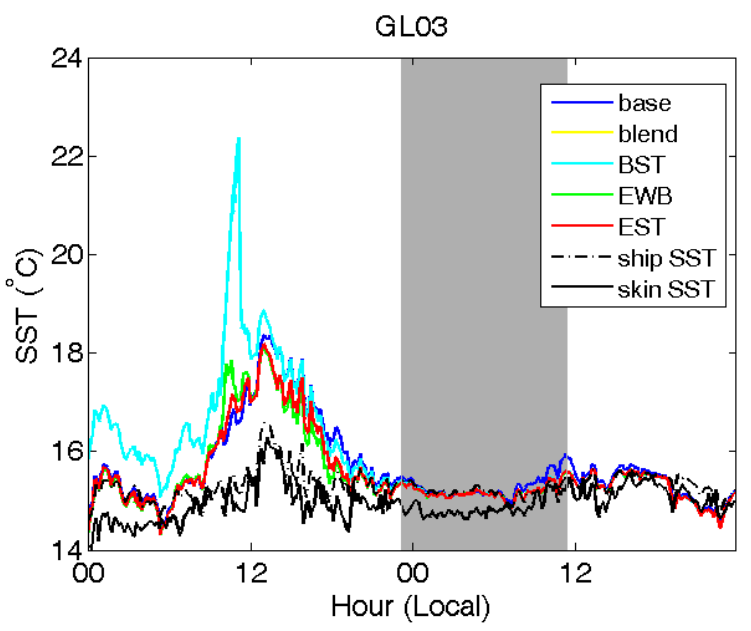

Fig. 2. Time-series of the five model simulations for the GL03 period plotted with observed skin and ship SST measurements. The grey vertical column represents the GL03 deployment period for SkinDeEP.

to BST in figures). A summary of the main differences between the five model versions discussed is shown in Table 2.

The air-sea heat fluxes used to force the Kantha and Clayson model versions were calculated using the TOGA COARE bulk flux algorithm and transfer coefficients from Fairall et al. (1996b). Meteorological data along with the calculated heat fluxes for the duration of the cruises were used as inputs for the model simulations. Values were interpolated to the resolution of the model time step and input to the model at each time step. The models were initialized with isothermal and constant salinity profiles based on observations from the research vessels at the start time of each run. Model execution began at midnight local solar time the day before the period of the comparison with the observed profiles to allow the model to spin up. While the modelled profiles were allowed to evolve freely, the modelled temperature profiles were relaxed to ship-based underway SST measurements at each time step to minimize advective effects. This involved the entire temperature profile being shifted such that the model temperature agrees with the measured subsurface temperature from the research vessel at the appropriate depth. The time step employed in the models was $1 \mathrm{~min}$. The vertical resolution of the model was $0.02 \mathrm{~m}$ between depths of 0.03 and $4.99 \mathrm{~m}$ and scaled to $0.15 \mathrm{~m}$ for depths thereafter. A finer resolution near the surface defined by temperature values at $0.0025,0.0075$ and $0.015 \mathrm{~m}$ depths was used to represent the upper few centimetres of the ocean. To extend temperature estimates from the shallowest layer of the model at $0.0025 \mathrm{~m}$ to the skin, the skin layer parameterization of Fairall et al. (1996a) is incorporated in the model.
Figure 2 illustrates the time evolution of the $\mathrm{SST}_{\text {skin }}$ estimations from the five models and observed temperatures for the GL03 case study. Both blended models produce identical temperature estimates for this period.

\section{Results}

In this section, the model simulations of the five model versions discussed in the previous section are compared to high resolution in situ measurements. For comparison, the modelsimulated and measured temperature profiles are bin averaged to $2 \mathrm{~cm}$ depth intervals, with increased resolution nearer the surface at depths of $0,0.0025,0.0075$ and $0.015 \mathrm{~m}$.

\subsection{Model performance in day-time stratification conditions}

Observational measurements from GC99 are used in the case of model validation in highly stratified conditions. The average solar irradiance is $802 \mathrm{~W} \mathrm{~m}^{-2}$ (peaking at $912 \mathrm{~W} \mathrm{~m}^{-2}$ ) and the mean wind speed is $1.1 \mathrm{~m} \mathrm{~s}^{-2}$ for the duration of the deployment (Fig. 1). Diurnal warming effects are very evident in this data set with warm-layer depths observed between 0.2 and $1.0 \mathrm{~m}$ throughout this deployment period (Fig. 3, top left). Comparing the simulations for each of the five different mixing schemes shows interesting results. Time-series plots for the five models show the temporal evolution of the temperature differences between modelled and measured profiles (Fig. 3). The optimal temperature difference interval $( \pm 0.2 \mathrm{~K})$ is coloured white in the plots. This interval represents required SST values to compute heat fluxes to within $\mathrm{a} \pm 10 \mathrm{~W} \mathrm{~m}^{-2}$ accuracy. The baseline model achieves the greatest white area of the three curves, providing good simulation results for this example of highly stratified conditions. This is mainly due to the baseline model predicting the most accurate warm-layer depth, resulting in a minimal mean temperature difference of $0.05 \mathrm{~K}$ from 0.5 to $5 \mathrm{~m}$ depth (Fig. 4). All five mixing schemes struggle to resolve the upper half metre correctly. It is important to note that it is difficult to conduct point-to-point comparisons given the potential for advective effects not considered in one-dimensional models. It is still interesting, however, to compare the relative performance of the different models. The two blended models achieve the highest temperature differences of the five models with an overestimation of $2.5 \mathrm{~K}$ for a brief period that morning. This occurs at the beginning of the deployment when the water column was observed to be well mixed (Fig. 3). All the models predict a diurnal warm layer at $1 \mathrm{~m}$ depth during this period, which accounts for the simulated temperature overestimations. The blended and baseline models overpredict temperatures during another period between 11:45 and 12:15 LT, when the solar heat flux drops to $700 \mathrm{~W} \mathrm{~m}^{-2}$ (Fig. 1). The observed warm-layer depth deepens by half a metre during this period (Fig. 3, top left). The 
Table 3. Standard deviations associated with the mean temperature difference profiles for the three case studies.

\begin{tabular}{llllll}
\hline Region & Base & EWB & Blend & EST & BST \\
\hline GC99 & 0.0855 & 0.0947 & 0.0826 & 0.0957 & 0.0870 \\
GL03 & 0.0906 & 0.0906 & 0.0939 & 0.0909 & 0.0939 \\
IO07 & 0.0348 & 0.0347 & 0.0348 & 0.0356 & 0.0355 \\
\hline
\end{tabular}

five models do not simulate this temporary deepening which could be related to their one-dimensional nature. The blended and baseline models strongly overestimate temperature during this period (Fig. 2), which strongly affects the models' overall performance. The enhanced models perform well in this brief period, which is due to the overestimated warmlayer depths now matching the observations (Fig. 3).

The models are best compared by averaging their performance over multiple events. Mean temperature profiles for the five model versions were computed for the duration of GC99 (Fig. 4). The standard deviations corresponding to these mean temperature profiles are given in Table 3, showing to be in close proximity of each other. On average the baseline mixing model overpredicts the $\mathrm{SST}_{\text {Skin }}$ value by $0.28 \mathrm{~K}$. The enhanced wave breaking and solar transmission models underpredict SST $_{\text {Skin }}$ values by $0.85 \mathrm{~K}$ and $1.0 \mathrm{~K}$ respectively, for the entire deployment while the blended model over predicts $\mathrm{SST}_{\text {Skin }}$ by $0.7 \mathrm{~K}$ (Fig. 4). The blended solar transmission model gives the best results as it under predicts $\mathrm{SST}_{\text {Skin }}$ by $0.11 \mathrm{~K}$ and also provides the best results down to a depth of $0.1 \mathrm{~m}$.

The enhanced wave breaking and solar transmission models predict deeper than observed warm-layer depths in Fig. 4. This affects the simulations by underestimating temperature within the observed warm layer and overestimating the temperature approximately $1 \mathrm{~m}$ below this layer depth (Fig. 4). This is evident in the EWB and EST plots in Fig. 3, where the yellow coloured areas in the centre of the plots represent the temperature overestimation. This is due to the enhanced models overestimating mixing in the upper few metres. This overestimation of mixing deepens the diurnal thermocline and creates an underestimation in temperature in the layers above, which can be observed as the blue coloured areas.

\subsection{Model performance in nighttime conditions}

Observational measurements from GL03 are used to validate model simulations in conditions corresponding to nighttime cooling and the initiation of diurnal warming. The deployment started at 23:08 (CET) and continued throughout the night until 11:23 (CET) the next morning. The mean wind speed is $6.29 \pm 0.52 \mathrm{~m} \mathrm{~s}^{-1}$ and the solar heat flux steadily rises from 0 to $876 \mathrm{~W} \mathrm{~m}^{-2}$ due to the morning solar heating (Fig. 1). The modelled simulated and observational data were bin averaged to depth intervals of $2 \mathrm{~cm}$ for the 117 profiles,
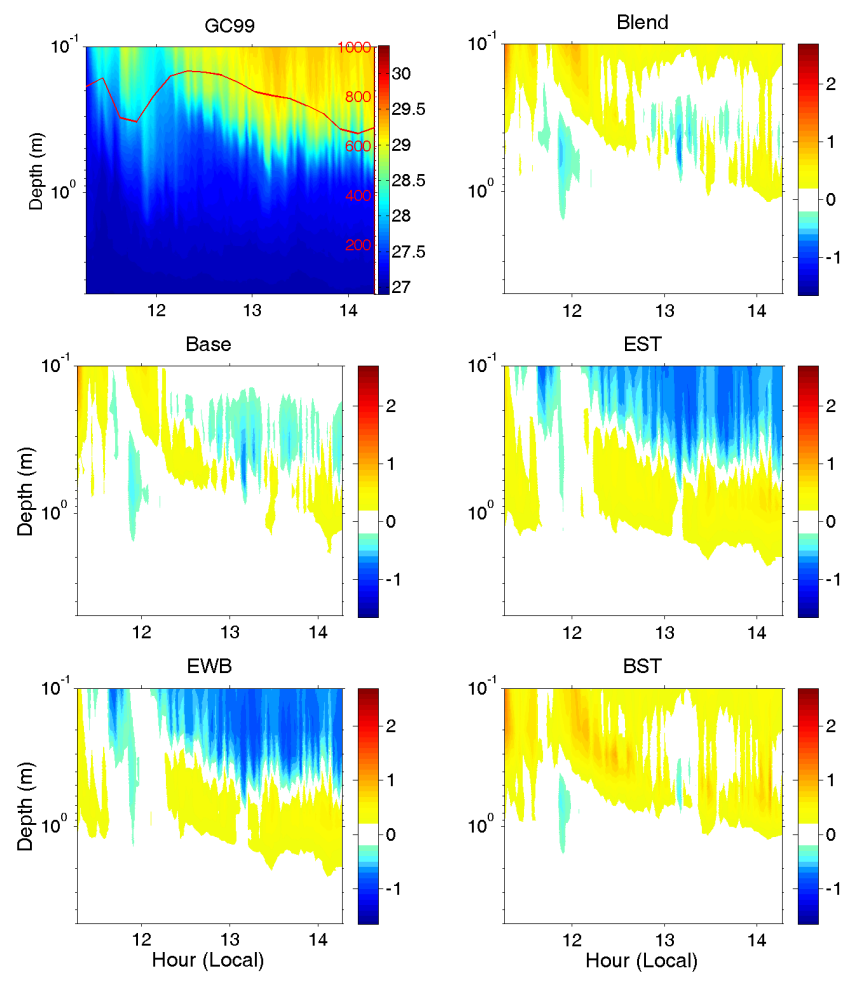

Fig. 3. Time-series temperature depth plots for the GC99 case study: observational plot and temperature difference (modelled minus observed) plots for the five model versions. Red curve represents observed solar irradiance $\left(\mathrm{W} \mathrm{m}^{-2}\right)$. The white area used represents an ideal $\Delta T$ of $\pm 0.2 \mathrm{~K}$.

with a higher resolution near the surface like that used in the previous section.

The plots (Fig. 5) show the times series of the measured profiles and temperature differences (model minus measured) of the five model versions for this period. Due to the small temperature changes observed, the white temperature difference interval represents $0.1 \mathrm{~K}$ for clarity (Fig. 5). The measured time-series plot (Fig. 5) shows a well mixed water column for most of the deployment period. A warm layer is formed at 10:00 LT with the increase of morning solar heating. The plot in Fig. 6 shows the mean temperature difference profile of the modelled minus the measured profiles for the deployment. The enhanced model and blended model simulations become quite singular (Fig. 6). The five models provide a mean temperature overestimation of $0.05 \mathrm{~K}$ from 0.0025 to $5 \mathrm{~m}$ depth, while the baseline model over predicts by $0.085 \mathrm{~K}$. All the models struggle to simulate the cool skin temperature correctly. The cool skin correction applied in the models was too weak (Fig. 6) and the simulated $\mathrm{SST}_{\text {Skin }}$ values were overestimated by nearly $0.3 \mathrm{~K}$. It is clear that the enhanced and blended models simulated the depth of the diurnal warm layer quite well as the temperature difference profile in Fig. 6 is relatively straight. The baseline model simulates a shallow, diurnal mixed layer which can 


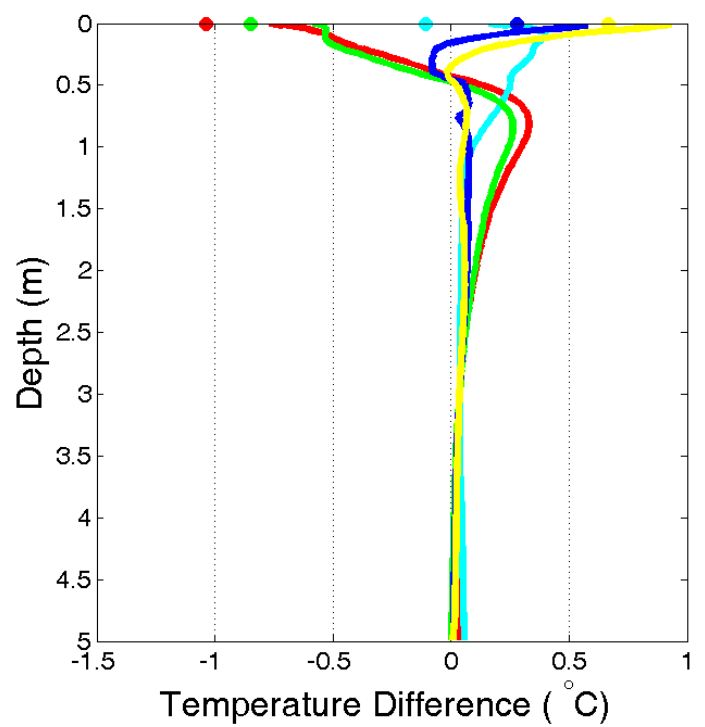

Fig. 4. GC99 data set: differences between the modelled and in situ measurements for the Base (blue), Blend (yellow), EWB (green), EST (red) and BST (cyan) models. The surface points are the differences between modelled and M-AERI skin temperatures.

be observed in Fig. 6, as the temperature difference curve changes slope rapidly below $2 \mathrm{~m}$ depth. Due to this, the temperature has been overestimated near the surface and underestimated below the observed mixed layer (Fig. 5). The enhanced and blended models are within the $\pm 0.2 \mathrm{~K}$ temperature difference. It is evident that the enhanced and blended models produce the best results for this period for nighttime well mixed conditions.

\subsection{Model performance for day-night transition}

ASIP measured temperature profiles from the IO07 data set are used in this study to validate the models' performance in the highly stratified Cirene region of the Indian-Pacific warm pool. The downwelling shortwave radiation and wind speed for this modelling period are illustrated in Fig. 1. The deployment takes place over nighttime and continues for a brief period after sunrise. The measuring period begins at 19:02 LT with a diurnal warm-layer depth of $5 \mathrm{~m}$ and a surface amplitude of $0.7 \mathrm{~K}$. A total of 72 profile measurements, spaced approximately $10 \mathrm{~min}$ apart, run until 06:21 LT the next morning. The warm-layer depth increases to $20 \mathrm{~m}$ and surface amplitude reduces to $0.1 \mathrm{~K}$ over the period. A timeseries plot of the observed temperature structure of the upper $5 \mathrm{~m}$ can be observed (Fig. 7, top left). ASIP profiling ceased between 00:28 and 01:41 LT, explaining the abrupt temperature change in the middle of the time-series plot.

Time-series plots of the temperature difference for the five model versions against observations are shown for this period (Fig. 7). It is evident that the temperature simulations struggle to replicate observations. The models underestimate the
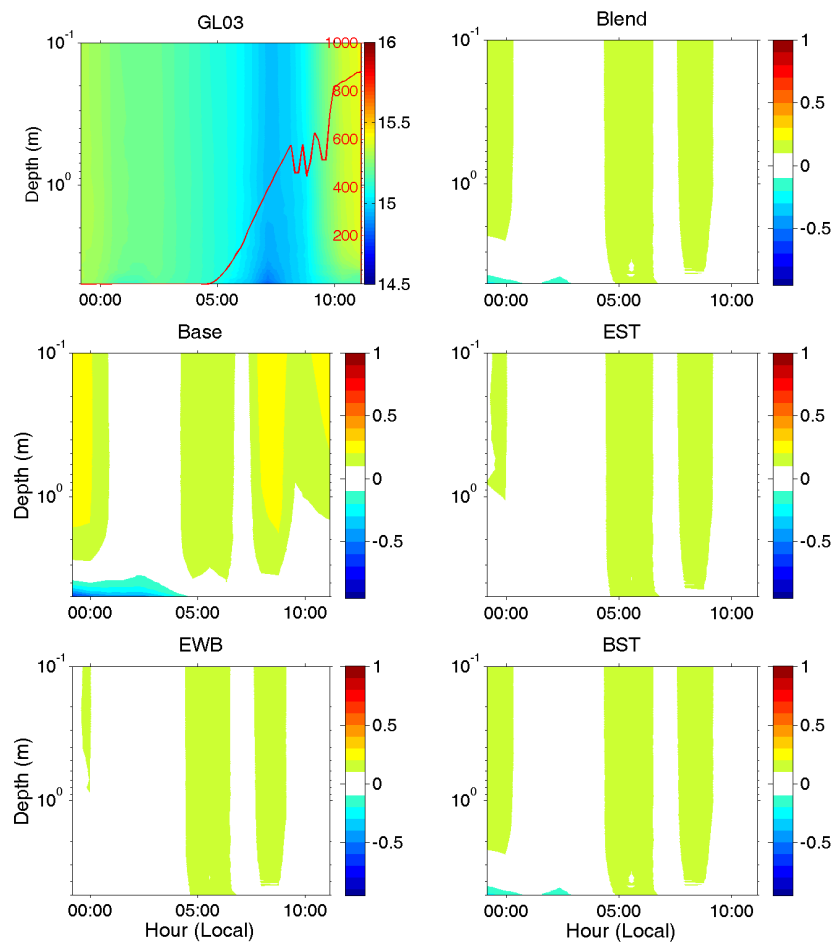

Fig. 5. Time-series temperature-depth plots for the GL03 case study: observational plot and temperature difference (modelled minus observed) plots for the five model versions. Red curve represents observed solar irradiance $\left(\mathrm{W} \mathrm{m}^{-2}\right)$. The white area used represents an ideal $\Delta T \mathrm{~T}$ of $\pm 0.1 \mathrm{~K}$.

temperature for the majority of the deployment, caused by all the models estimating the warm-layer depth deeper than that of the observations. The models quickly react to the solar heating toward the end of the measuring period, increasing the temperature of the upper $1 \mathrm{~m}$ by $0.4 \mathrm{~K}$. The observed data shows no signs of warming in the upper metre during this period of solar heating.

The mean temperature profiles for each of the models are shown in Fig. 8. The five models strongly underestimate the temperature in the upper $5 \mathrm{~m}$. The diagonally shaped temperature profile in Fig. 8 shows that this underestimation is caused by the models incorrectly estimating the warm-layer depth well below that of the observed warm-layer depth. The high sensitivity of the models to solar heat flux is evident in the curve above $0.5 \mathrm{~m}$ depth in Fig. 8 . All the models produce very similar mean temperature profiles and standard deviations (Table 3). All models, on average, underestimate the top metre of the warm layer by $0.45 \mathrm{~K}$.

The cool skin correction model applied in the simulations is on average $0.17 \mathrm{~K}$ above the required correction (Fig. 8).

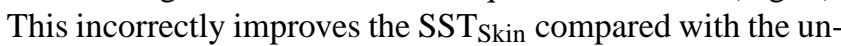
derestimated $\mathrm{SST}_{\text {Subskin }}$ directly beneath. 


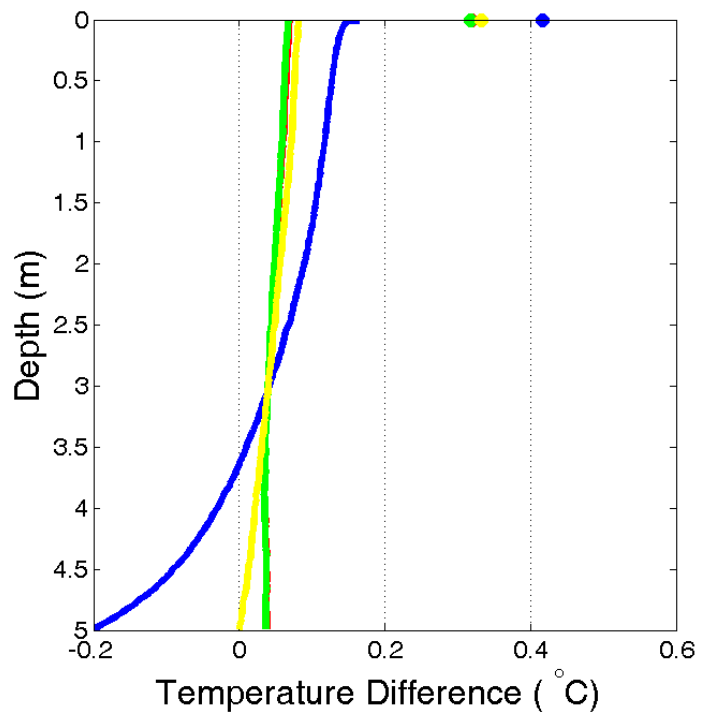

Fig. 6. GL03 data set: differences between the modelled and in situ measurements for the Base (blue), Blend (yellow), EWB (green), EST (red) and BST (cyan) models. The surface points are the differences between modelled and M-AERI skin temperatures.

\subsection{Overall model performance}

In this section, all the available observed profiles (1165) are collectively used to validate the five model versions. A mean temperature profile for these profiles is shown in Fig. 9. A temperature gradient exists at $0.2 \mathrm{~m}$ depth, implying that strong effects of stratification are evident. The mean diurnal warming $\left(\mathrm{SST}_{\text {Subskin }}-T_{\text {Depth }}\right.$ ) is about $0.7 \mathrm{~K}$ for all observations.

The mean temperature difference profiles for the five models using all of the available profiles are shown in Fig. 10. The conditions are mixed in a low to moderate wind environment and with strong solar heating present (Fig. 1). The majority of deployments show strong characteristics of stratification in the water column (Fig. 9). Overall, the baseline model simulations provide the most accurate $\mathrm{SST}_{\text {Skin }}$ values with a slight mean underestimation of $0.016 \mathrm{~K}$. The blended model also works well with a mean overestimation of $0.045 \mathrm{~K}$. The enhanced models show strong temperature underestimations throughout the warm layer (Fig. 7) which strongly affects the cool-skin temperature estimations. The enhanced models underestimate $\mathrm{SST}_{\text {Skin }}$ by $0.30 \mathrm{~K}$. The blended solar transmission model underestimates $\mathrm{SST}_{\text {Skin }}$ by $0.12 \mathrm{~K}$.

Comparing Figs. 9 and 10, it is clear that the baseline model predicts the most accurate mixed-layer depth, within negligible temperature variations up to $0.1 \mathrm{~m}$ depth. A minor temperature overestimation occurs above $0.1 \mathrm{~m}$ depth for the baseline and blended model versions, caused by the use of the nine-band solar absorption model. The addition of the OS00 solar transmission model corrects this warming overestimation above this depth, which can be observed
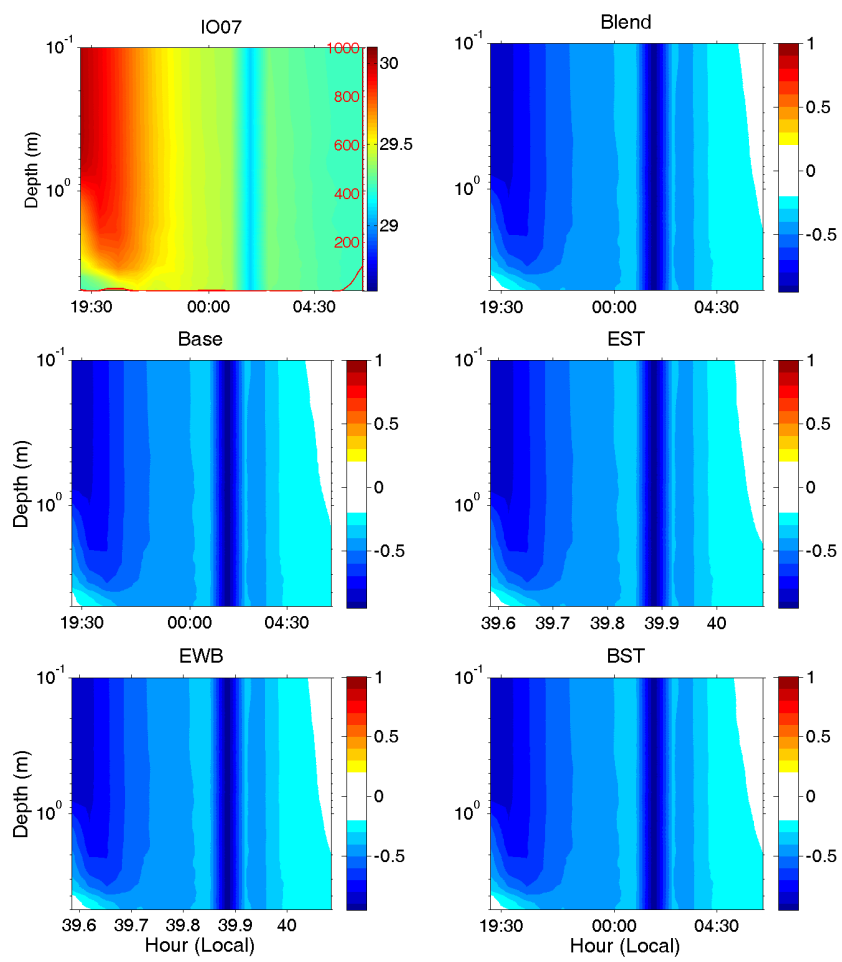

Fig. 7. Time-series temperature-depth plots for the IO07 case study: observational plot and temperature difference (modelled minus observed) plots for the five model versions. Red curve represents observed solar irradiance $\left(\mathrm{W} \mathrm{m}^{-2}\right)$. The white area used represents an ideal $\Delta T$ of $\pm 0.2 \mathrm{~K}$.

from the temperature profile simulated by the blended solar transmission model in Fig. 10. The blended solar transmission model performs the best for depths from the subskin to $0.1 \mathrm{~m}$, and achieves the closest SST $_{\text {Subskin }}$ of all five models with $-0.05 \mathrm{~K}$, with the baseline model achieving $0.06 \mathrm{~K}$. The enhanced models show strong temperature underestimations above $0.2 \mathrm{~m}$ depth, influenced by the increased mixing parameters associated with the addition of the $\mathrm{KC} 04$ enhancement. The little difference between the results from the two enhanced model versions implies that the OSO0 solar transmission enhancement has a low impact on the results compared to that of the $\mathrm{KC} 04$ enhancement.

The cool-skin correction in the plot (Fig. 10) is very strong for all the models. It causes an underestimation of $0.09 \mathrm{~K}$ with respect to the warm-layer correction. In particular, this has a strong impact on the overall performance of the blended solar transmission model.

\section{Conclusions}

A strong variability in the results was shown to exist between the models for highly stratified conditions (Fig. 4). Overall, the baseline model produces the most accurate temperature estimates for the cruise periods used in this study. 


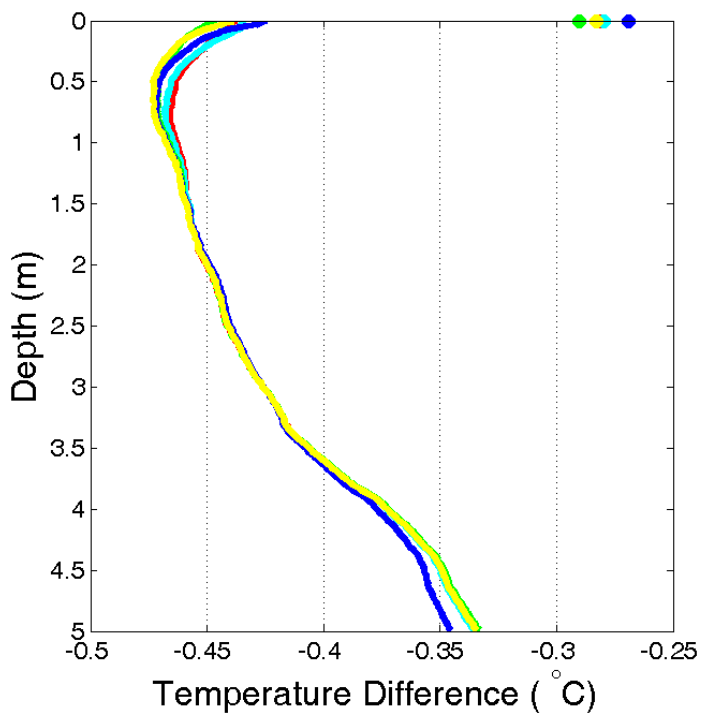

Fig. 8. IO07 data set: differences between the modelled and in situ measurements for the Base (blue), Blend (yellow), EWB (green), EST (red) and BST (cyan) models. The surface points are the differences between modelled and M-AERI skin temperatures.

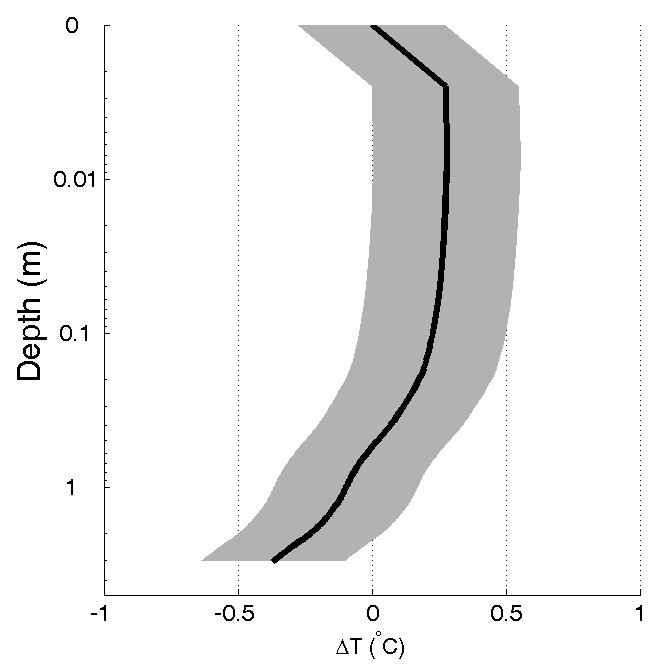

Fig. 9. Mean observed temperature profile for all available data (1165 profiles collectively from GC99, GL03 and IO07 data sets) referenced to the mean $\mathrm{SST}_{\text {Skin }}$ value. The shaded region represents the $95 \%$ confidence interval.

The enhanced models showed a strong temperature underestimation in the diurnal mixed layer for simulations in highly stratified conditions. This is caused by the models' overestimation of the mixed-layer depth, a direct result of the models' high prediction of mixing near the surface. This is in agreement with previous studies (Kantha and Clayson, 2004; Ohlmann and Siegel, 2000) which have recorded reduced temperatures in the diurnal mixed layer and increased mixedlayer depths. The enhanced models work well when wind induced mixing at the surface is a dominant factor, creat-

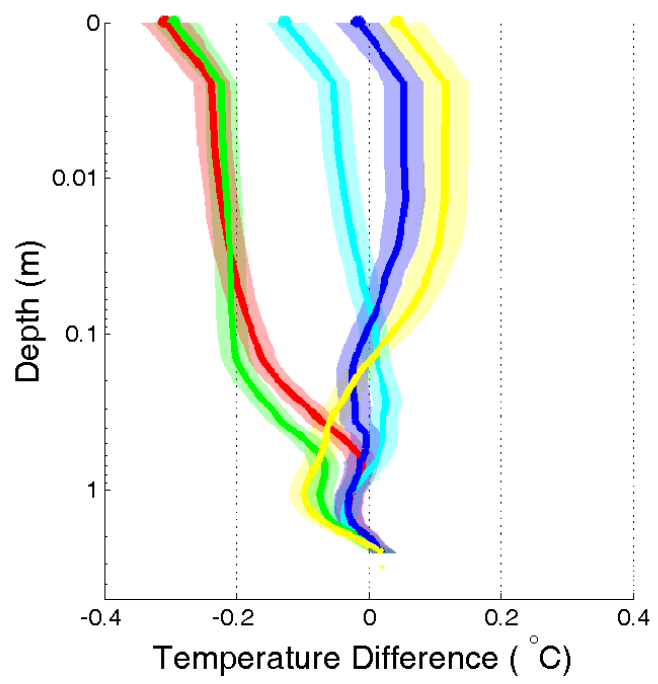

Fig. 10. Mean temperature difference profile for all available data (1165 profiles collectively from the GC99, GL03 and IO07 data sets). The blue, yellow, green, red and cyan profiles represent the mean temperature difference profiles of the Base, Blend, EWB, EST and BST models, respectively. The transparent colour-coded regions represent the $95 \%$ confidence intervals.

ing a well-mixed upper ocean. For this study, the KarmanPrandtl law of the wall assumption provides more accurate SST values than the estimates achieved from the $\mathrm{KC} 04$ enhanced wave breaking model when the upper ocean is maximally stratified. Overall, the OSO0 solar transmission model provides more accurate temperature estimates in the diurnal mixed layer compared to the nine-band absorption model. The blended solar transmission model which transitions between the two surface turbulence approaches and includes the OSO0 model provides very good results immediately below the surface.

The cool-skin correction applied in the models produced underestimations when compared to the measured SST $_{\text {Skin }}$. On average the cool-skin correction underestimated SST $_{\text {Skin }}$ by $0.09 \mathrm{~K}$ for all the models. A revised cool-skin correction could considerably improve the performance of the blended solar transmission model (Fig. 10).

Acknowledgements. Support for B. Scanlon was provided by the Research Council of Norway (Grant 207541: OILWAVE) and the EU FP7 project CARBOCHANGE under grant agreement no. 264879. B. Ward was supported by the FP7 International Reintegration Grant IRG-224776. The captain and crew of the R/V Melville, R/V Urania, and R/V Suroit are thanked for their able assistance. We are very grateful to Peter Minnett who provided the M-AERI data for this study.

Edited by: R. Sabia 


\section{References}

Agrawal, Y. C., Terray, E. A., Donelan, M. A., Hwang, P. A., A. J. Williams III, Drennan, W. M., Kahma, K. K., and Kitaigorodskii, S. A.: Enhanced dissipation of kinetic energy beneath surface waves, Nature, 359, 219-220, 1992.

Craig, P. D. and Banner, M. L.: Modelling wave-enhanced turbulence in the ocean surface layer, J. Phys. Oceanogr., 24, 25462559, 1994.

Donlon, C. J.: Radiometric Observations of the Sea Surface and Atmosphere (ROSSA) Cruise, Report and Data Summary, Joint Res. Centre, Brussels, Belgium, 1999.

Donlon, C. J., Minnett, P. J., Gentemann, C., Nightingale, T. J., Barton, I. J., Ward, B., and Murray, J.: Toward improved validation of satellite sea surface skin temperature measurements for climate research, J. Climate, 15, 353-369, 2002.

Fairall, C. W., Bradley, E. F., Godfrey, J. S., Wick, G. A., Edson, J. B., and Young, G. S.: Cool-skin and warm-layer effects on sea surface temperature, J. Geophys. Res., 101, 1295-1308, 1996a.

Fairall, C. W., Bradley, E. F., Rogers, D. P., Edson, J. B., and Young, G. S.: Bulk Parameterization of air-sea fluxes for Tropical Ocean-Global Atmosphere Coupled-Ocean Atmosphere Response Experiment, J. Geophys. Res., 101, 3747-3764, 1996b.

Gentemann, C. L. and Minnett, P. J.: Radiometric measurements of ocean surface thermal variability, J. Geophys. Res., 113, C08017, doi:10.1029/2007JC004540, 2009.

Gentemann, C. L., Minnett, P. J., and Ward, B.: Profiles of ocean surface heating (POSH): A new model of upper ocean diurnal warming, J. Geophys. Res., 114, C07017, doi:10.1029/2008JC004825, 2009.

Kantha, L. H.: On an improved model for the turbulent PBL, J. Atmos. Sci., 60, 2239-2246, 2003.

Kantha, L. H. and Clayson, C. A.: An improved mixed layer model for geophysical applications, J. Geophys. Res., 99, 2523525266, 1994.

Kantha, L. H. and Clayson, C. A.: On the effect of surface gravity waves on mixing in the oceanic mixed layer, Ocean Modelling, 6, 101-124, 2004.

Minnett, P. J., Knuteson, R. O., Best, F. A., Osborne, B. J., Hanafin, J. A., and Brown, O. B.: The Marine-Atmospheric Emitted Radiance Interfrometer (M-AERI), a high accuracy, seagoing infrared spectroradiometer, J. Atmos. Ocean. Technol., 18, 9941013, 2001.

Ohlmann, J. C. and Siegel, D. A.: Ocean Radiant heating, Part II: Parameterizing solar radiation transmission through the upper ocean, J. Phys. Oceanogr., 30, 1849-1865, 2000.
Ohlmann, J. C., Siegel, D. A., and Washburn, L.: Radiant heating of the western equatorial Pacific during TOGA-COARE, J. Geophys. Res., 103, 5379-5395, 1998.

Paulson, C. A. and Simpson, J. J.: The temperature difference across the coolskin of the ocean, J. Geophys. Res., 86, 11044-11054, 1981.

Price, J. F., Weller, R. A., and Pinkel, R.: Diurnal cycling: Observations and models of the upper ocean response to diurnal heating, cooling and wind mixing, J. Geophys. Res., 91, 8411-8427, 1986.

Soloviev, A. V. and Lukas, R.: Observation of spatial variability of diurnal thermocline and rain-formed halocline in the western $\mathrm{Pa}$ cific warm pool, J. Phys. Oceanogr., 26, 2529-2538, 1996.

Soloviev, A. and Schluessel, P.: Evolution of cool skin and direct air-sea gas transfer coefficient during daytime, Bound.-Lay. Meteorol., 77, 45-68, 1996.

Stramma, L., Cornillon, P., Weller, R. A., Price, J. F., and Briscoe, M.: Large diurnal sea surface temperature variability: satellite and in situ measurements, J. Phys. Oceanogr., 16, 827-837, 1986.

Terray, E. A., Donelan, M. A., Agrawal, Y. C., Drennan, W. M., Kahma, K. K., A. J. Williams III, Hwang, P. A., and Kitaigorodskii, S. A.: Estimates of kinetic energy dissipation under breaking waves, J. Phys. Oceanogr., 26, 792-807, 1996.

Ward, B.: Near-surface ocean temperature, J. Geophys. Res., 109, C02004, doi:10.1029/2004JC002689, 2006.

Ward, B., Wanninkhof, R., McGillis, W. R., Jessup, A. T., DeGrandpre, M. D., Hare, J. E., and Edson, J. B.: Biases in the air-sea flux of $\mathrm{CO}_{2}$ resulting from ocean surface temperature gradients, J. Geophys. Res., 109, C08S08, doi:10.1029/2003JC001800, 2004a.

Ward, B., Wanninkhof, R., Minnett, P. J., and Head, M.: SkinDeEP: A Profiling Instrument for Upper Decameter Sea Surface Measurements, J. Atmos. Ocean. Technol., 21, 207-222, 2004b.

Ward, B., Fristedt, T., Callaghan, A. H., Sutherland, G., Sanchez, X., Vialard, J., and Lilley, J. M.: The Air-Sea Interaction Profiler (ASIP): An Autonomous Upwardly-Rising Profiler for Microstructure Measurements in the Upper Ocean, J. Atmos. Ocean. Technol., submitted, 2012.

Webster, P. J., Clayson, C. A., and Curry, J. A.: Clouds, radiation, and the diurnal cycle of sea surface temperature in the tropical western Pacific, J. Climatol., 9, 1712-1730, 1996.

Weller, R. and Price, J. F.: Langmuir circulations in the oceanic surface layer, Deep-Sea Res., 35, 711-747, 1988.

Wick, G. A., Emery, W. J., Kantha, L. H., and Schlüssel, P.: The behavior of the bulk-skin sea surface temperature difference under varying wind speed and heat flux, J. Phys. Oceanogr., 26, 19691988, 1996. 